\title{
Juvenile competitive triathlete after cardiotoxic anthracycline therapy for Acute Myeloid Leukemia
}

\author{
Pia von Korn ${ }^{1}$, Manfred Vogt ${ }^{2}$, Renate Oberhoffer ${ }^{1}$, Peter Ewert ${ }^{2}$ and Jan Müller ${ }^{1,2^{*}}$
}

\begin{abstract}
Objective: The treatment of Acute Myeloid Leukemia (AML) leads to several functional limitations. Especially cardiac burden following cardiotoxic chemotherapy, which limits exercise and competitive sport in the long-term survivors.

Subject and methods: We report on a young female amateur triathlete born in 1997, who was diagnosed with AML at the age of fifteen. She had chemotherapy with a cumulative dose of about $1000 \mathrm{mg} / \mathrm{m}^{2}$ anthracyclines and allogeneic stem cell transplantation which was successful, but she suffered from cardiotoxic systolic heart failure with a left ventricular ejection fraction (LVEF) $<55 \%$ and an impaired peak oxygen uptake of $23.2 \mathrm{ml} / \mathrm{min} / \mathrm{kg}$ and $53 \%$ of predicted, respectively. After medical examination and counselling with a sport scientist she started a tailored training of aerobic exercise. She was evaluated at regular intervals which resulted in increasing the training load and volume. Eventually her training hours was stepwise increased to $12 \mathrm{~h}$ training per week, which includes high intensity intervals.
\end{abstract}

Results: Within almost 3 years, her exercise performance improved tremendously. Workload doubled from $2.1 \mathrm{~W} / \mathrm{kg}$ to $4.2 \mathrm{~W} / \mathrm{kg}$, peak oxygen uptake increased from $23.2 \mathrm{ml} / \mathrm{min} / \mathrm{kg}$ to $49.1 \mathrm{ml} / \mathrm{min} / \mathrm{kg}$ and from 53 to $135 \%$, respectively. Moreover, she participated in several competitions. However, LVEF remains almost unchanged.

Conclusion: With the right training and under medical surveillance competitive exercise with an anthracycline-damaged heart is still achievable. Moreover, competitive training and exercise seems to be safe and feasible.

Keywords: Acute myeloid leukemia, Anthracyclines, Exercise, Training, Rehabilitation

\section{Introduction}

Treatment of "Acute Myeloid Leukemia" (AML) includes chemotherapy with anthracyclines, whose cardiotoxicity is well documented in cancer literature [1]. Higher doses of anthracyclines $\left(>250 \mathrm{mg} / \mathrm{m}^{2}\right)$ are directly associated with an exponentially higher risk of developing cardiac pathogenesis [2, 3]. Moreover, anthracycline leads to cardiac complications like cardiomyopathy, reduced left ventricular ejection fraction $(<55 \%)$ and higher arterial stiffness in $16 \%$ of all AML-long-term-survivors $[1,4,5]$. Since children and young adults tend to suffer from this

\footnotetext{
* Correspondence: j.mueller@tum.de

${ }^{1}$ Institute of Preventive Pediatrics, Technische Universität München, Munich, Germany

${ }^{2}$ Department of Pediatric Cardiology and Congenital Heart Disease, Deutsches Herzzentrum München, Technische Universität München, Lazarettstr. 36, D-80636 Munich, Germany
}

disease a closer look towards long-term functional outcome of every single survivor has to be taken into account.

Contemporary, curative treatment of chemotherapeutic protocols, like AFM-BFM ${ }^{1}$, reduce the dosage of cardiotoxic anthracycline by replacing Idarubicin by L-DNR for less treatment-related mortality [6, 7]. However, studies support that also low doses of anthracyclines are still cardiotoxic [8]. Impaired cardiac response to exercise and reduced exercise capacity is frequently seen in cancer survivors treated with cardiotoxic drugs [9]. For that reason tailored exercise recommendations should be given to those patients to improve or even normalize exercise capacity [9].

Even though recent studies demonstrate comparable exercise capacity of adolescent cancer survivors and healthy controls [9] there are still many patients that suffer from 
exercise limitations [10]. Information regarding young competitive athlete's after cancer therapy is still lacking.

\section{Case report}

We report on a female amateur triathlete born in 1997 who is suffering from AML diagnosed in September 2011 at the age of 15 . She received the AML-BFM 2004 chemotherapy protocol with liposomal Daunorubicin, Mitoxantron and Idarubicin as cardiotoxic anthracyclines and further allogeneic bone marrow transplantation in January 2012. Her therapeutic regime contains a dose about $750 \mathrm{mg}$ per square meter body surface anthracyclines, summarized to her bodily parameters at that time multiplied with $1,43 \mathrm{~m}^{2}$ (cumulative dose of all given protocols: 1.072,5 mg).

Her medication nowadays consists of diuretics, Beta blocker, ACE-inhibitor and an additional hormone therapy ${ }^{2}$. No relapse was found since then.

In December 2012, she received her first echocardiography and the cardiopulmonary exercise test (CPET) on electronic braked bicycle ergometer at our institution. Echocardiography revealed limited contractility of the normal sizes left ventricle (Ejection fraction 50-55\%). Exercise capacity was severely reduced with a peak VO2 of $23.3 \mathrm{ml} / \mathrm{min} / \mathrm{kg}$ and peak workload of $88 \mathrm{~W}$ and 2.07
$\mathrm{W} / \mathrm{kg}$, respectively. Especially the cardiac panels from the nine panel plot derived from CPET revealed a limited cardiac response to exercise (Fig. 1).

Afterwards we (athlete, sport scientist, medical doctors and parents), designed a training schedule with her coach including swimming, walking and cycling starting with just aerobic intensities. Re-evaluation was performed approximately every 6 month with the same procedures, training was adjusts, intensity and duration was progressively increased up to $12-14 \mathrm{~h}$ a week. Over the past three years exercise capacity increased tremendously to a peak $\mathrm{VO} 2$ of $49.1 \mathrm{ml} / \mathrm{min} / \mathrm{kg}$ and peak workload of $224 \mathrm{~W}$ and $4.23 \mathrm{~W} / \mathrm{kg}$, respectively (Fig. 1 and Table 1 ). Her final CPET showed a perfect cardiac response to exercise with a well increasing $\mathrm{VO} 2$, heart rate and systolic blood pressure during exercise. She also competed in sprint triathlons.

In contrast her cardiac function derived from echocardiography shows only a slight improvement in contractility (Ejection fraction 55-60\%).

\section{Discussion}

Leisure-time physical activity is associated with reduced cancer incidence [11] and exercise interventions in adult's cancer patients also provide positive results $[12,13]$. Also
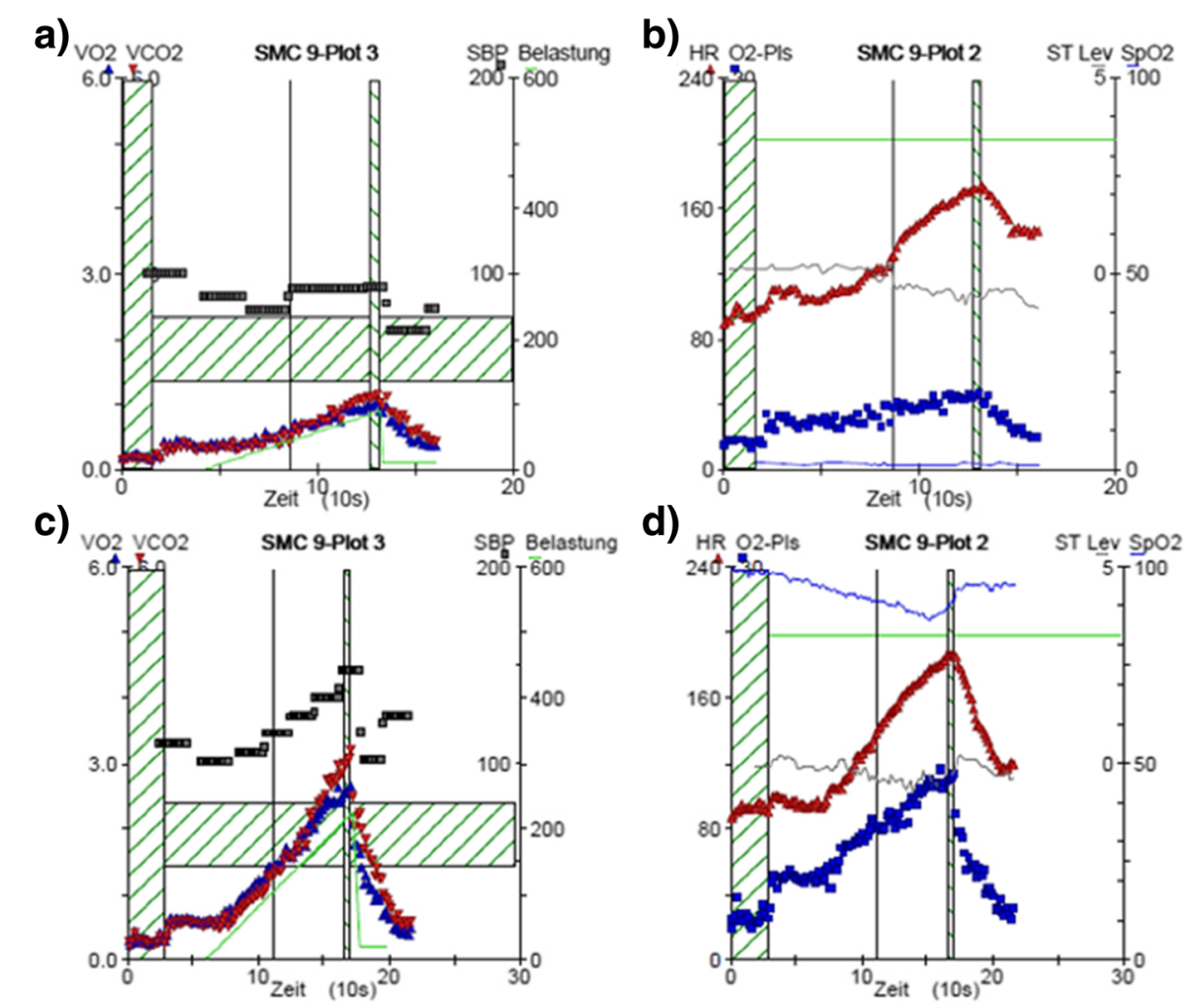

Fig. 1 Cardiac response to exercise from cardiopulmonary exercise testing. First cardiopulmonary exercise test almost one year after therapy for Acute Myeloid Leukemia showed a drop in systolic blood pressure throughout exercise (a) and limitations in oxygen uptake (a) and heart rate (b). Four years after therapy for Acute Myeloid Leukemia and continuous competitive exercise training showing a tremendous improved blood pressure (c), oxygen and heart rate response to exercise (d) 
Table 1 Measures from cardiopulmonary exercise testing

\begin{tabular}{|c|c|c|c|c|c|c|}
\hline & 06.12 .2012 & 06.06 .2013 & 26.09 .2013 & 27.03 .2014 & 11.11 .2014 & 29.07 .2015 \\
\hline Resting Heart rate (beats per minute) & 95 & 98 & 79 & 71 & 86 & 93 \\
\hline Peak Heart rate (beats per minute) & 173 & 179 & 179 & 190 & 190 & 187 \\
\hline Resting Blood Pressure $(\mathrm{mmHg})$ & $100 / 72$ & $85 / 65$ & $99 / 62$ & $93 / 63$ & $83 / 57$ & $110 / 62$ \\
\hline Peak Blood Pressure $(\mathrm{mmHg})$ & $93 / 58$ & - & $113 / 68$ & $136 / 80$ & $120 / 66$ & $147 / 74$ \\
\hline Peak oxygen uptake (ml/min/kg) & 23.2 & 28.8 & 32.4 & 35.7 & 40.2 & 49.1 \\
\hline Peak oxygen uptake (\% predicted) & 53 & 78 & 82 & 91 & 107 & 135 \\
\hline Workload (Watt/kg) & 2.07 & 2.68 & 3.02 & 3.88 & 3.92 & 4.23 \\
\hline
\end{tabular}

competitive sports after successful cancer treatment is well documented in adults, but can be questionable, eg in the professional bicyclist Lance Armstrong.

The evidence for benefits in children is rather low. Decreased physical fitness and activity is reported in childhood cancer survivors. Unfortunately, exercise intervention studies in childhood cancer survivors were of moderate to very low quality [14].

The recent case also demonstrates a well-performed re-entry after leukemia into competitive sport, to the contrary of the majority of mostly sedentary pediatric leukemia patients [15]. Not only fighting cancer successfully, our individual developed tremendous improvements in terms of body condition and her cardiopulmonary system after therapy. Healthy cohorts showed a peak oxygen uptake of about $38.1 \mathrm{ml} / \mathrm{min} / \mathrm{kg}$, whereas our patient had a peak oxygen uptake of $49.1 \mathrm{ml} / \mathrm{min} / \mathrm{kg}$ (about $30 \%$ over average) 2 years after cancer treatment [9].

Although cardiotoxic complications were diagnosed, she started to train with low frequencies and intensities until achieving an adequate performance level from which she intensified her training with anaerobic content in high-intensity interval training (HIT). HIT is a contemporary training method not only in athletes but rather in cardiac rehabilitation [16]. HIT had shown increases in skeletal muscle oxidative capacity and endurance performance. More precisely that means a higher number and size of mitochondria, less lactate production, better utilization and energy supply during exercise and improvements in insulin sensitivity. HIT drives the metabolism much harder than regular aerobic training and adaptation in endurance and strength occur faster. Recent studies prove the beneficial effect of combined HIT and moderate training also for cancer patients [17, 18].

The structured training also led to further physiological adaptations beyond the increase in peak oxygen uptake, what substantiates findings from other investigations like improved physical and overall health benefits, immune cell recovery and body composition after hospitalization and stem cell transplantation $[19,20]$. Also an appropriate blood pressure rise during exercise could be restored as well as a rise in the oxygen pulse, a surrogate for the forward stroke volume (Fig. 1a in comparison to 1b). Whereas cardiac response to exercise was extremely poor directly after therapy, in her last CPET the increase in blood pressure and oxygen pulse was very well regained over the training period of 30 months in 7 CPETs. All parameters, peak oxygen uptake, oxygen pulse and blood pressure, are predictive for survival and hospitalization in the long-term. The improvement of all means therefore a tremendous improvement in prognosis. This result, achieved with a heart harmed with a high dose of cardiotoxic anthracyclines must be seen as a pioneering success of training after cancer treatment in an adolescent.

The outline at this point is the fact that competitive sport after cancer therapy is possible only in alliance with optimal medical care, close physical examinations and tailored training schedules. When our patient reached adulthood, her body has to face the lifelong heart insufficiency medication and possible side effects and further long-term sequels could appear. However, due to medical and treatment-related sequelae, especially children and young adults have to be included in active and strengthening interventions, where they keep their physical feeling already during acute therapy [21]. Aftercare has to include widespread rehabilitation, where physical exercise and an active lifestyle has to be part of normality [22].

This case shows how cancer treatment-related toxicities and long-term sequels can be accomplished by strong will, physical capability and training effort. Moreover, it should serve as role model for all cancer survivors that suffer from heart burden and other bodily harm, whose sport and exercise was, and still is, a central part of their life.

\section{Endnotes}

${ }^{1}$ Acute Myeloid Leukemia Berlin-Frankfurt-Münster.

${ }^{2}$ Since $07 / 2012$ Carvedilol (3,125 mg - $\left.0-3,125 \mathrm{mg}\right)$, Enalapril (3,75 mg - $0-2,5 \mathrm{mg})$, Spironothiazid (50 mg - 0 - 0). Since 06/2013 Carvedilol (3,125 mg 0 - 3,125 mg), Digimerck pico $(0,05 \mathrm{mg}-0-0)$, Spironothiazid (25 mg - $0-0)$, Lisinopril (1,25 mg - 0-0). 


\section{Abbreviations}

AML: Acute Myeloid Leukemia; AMLBFM: Acute Myeloid Leukemia BerlinFrankfurt-Münster; CPET: Cardiopulmonary exercise test; HIT: High-intensity interval training; LVEF: Left ventricular ejection fraction; VO2: Oxygen uptake

\section{Acknowledgment}

We wish our patient (K.H.) all the best for the future and feel honored to accompany her on her long-term project "Road to Hawaii". This work was supported by the German Research Foundation (DFG) and the Technical University of Munich (TUM) in the framework of the Open Access Publishing Program.

We thank Sarmila Ganeshamoorthy for proofreading the manuscript.

\section{Funding}

None.

\section{Availability of data and materials}

Case report data is presented completely in the manuscript.

\section{Authors' contributions}

PvK was responsible for analyzing and processing of the data and drafted the manuscript. MV performed Ultrasound and gave important input for drafting and revising the manuscript. PW and RO gave important input for drafting and revising the manuscript. JM was responsible for conception and design of the case report and gave important input for drafting and revising the manuscript. All authors read and approved the final manuscript.

\section{Competing interests}

The authors declare that they have no competing interests.

\section{Ethics approval and consent to participate}

A general ethical approval was approved by the local ethical board (project number 1931/07). Specific Ethical approval was waived because of the pure retrospective character of the data and the written consent of the patient and guardian to publish their data anonymized.

Received: 13 May 2016 Accepted: 15 September 2016

Published online: 14 October 2016

\section{References}

1. Franco VI, Lipshultz SE. Cardiac complications in childhood cancer survivors treated with anthracyclines. Cardiol Young. 2015;25:107-16.

2. Berkman AM, Lakoski SG. Treatment, behavioral, and psychosocial components of cardiovascular disease risk among survivors of childhood and young adult cancer. J Am Heart Assoc. 2015;4:10

3. Yu HK, Yu W, Cheuk DK, Wong SJ, Chan GC, Cheung YF. New threedimensional speckle-tracking echocardiography identifies global impairment of left ventricular mechanics with a high sensitivity in childhood cancer survivors. J Am Soc Echocardiogr. 2013;26:846-52.

4. Barlogis $V$, Auquier $P$, Bertrand $Y$, Chastagner $P$, Plantaz D, Poiree M, Kanold J, Berbis J, Oudin C, Vercasson C, et al. Late cardiomyopathy in childhood acute myeloid leukemia survivors: a study from the LEA program. Haematologica. 2015;100:4

5. Armstrong GT, Joshi VM, Ness KK, Marwick TH, Zhang N, Srivastava D, Griffin BP, Grimm RA, Thomas J, Phelan D, et al. Comprehensive echocardiographic detection of treatment-related cardiac dysfunction in adult survivors of childhood cancer. J Am Coll Cardiol. 2015:65:2511-22.

6. Creutzig U, Zimmermann M, Dworzak MN, Ritter J, Schellong G, Reinhardt D. Development of a curative treatment within the AML-BFM studies. Klin Padiatr. 2013;225 Suppl 1:S79-86.

7. Creutzig U, Zimmermann M, Bourquin JP, Dworzak MN, Fleischhack G, Graf N, Klingebiel T, Kremens B, Lehrnbecher T, von Neuhoff C, et al. Randomized trial comparing liposomal daunorubicin with idarubicin as induction for pediatric acute myeloid leukemia: results from Study AML-BFM 2004. Blood. 2013;122:37-43.

8. Orgel E, Zung L, Ji LY, Finklestein J, Feusner J, Freyer DR. Early cardiac outcomes following contemporary treatment for childhood acute myeloid leukemia: A north American perspective. Pediatr Blood Cancer. 2013;60: 1528-33.
9. De Caro E, Fioredda F, Calevo MG, Smeraldi A, Saitta M, Hanau G, Faraci M, Grisolia F, Dini G, Pongiglione G, Haupt R. Exercise capacity in apparently healthy survivors of cancer. Arch Dis Child. 2006;91:47-51.

10. Seifart U, Lotze C, Dauelsberg T. Exercise and physical activity in oncological rehabilitation. Onkologe. 2011;17:898

11. Moore SC, Lee IM, Weiderpass E, Campbell PT, Sampson JN, Kitahara CM, Keadle SK, Arem H, Berrington de Gonzalez A, Hartge P, et al. Association of leisure-time physical activity with risk of 26 types of cancer in 1.44 million adults. JAMA Intern Med. 2016;176(6):816-25. doi:10.1001/jamainternmed.2016.

12. Winters-Stone KM, Schwartz A, Nail LM. A review of exercise interventions to improve bone health in adult cancer survivors. J Cancer Surviv. 2010:4: 187-201.

13. Ibrahim EM, Al-Homaidh A. Physical activity and survival after breast cancer diagnosis: meta-analysis of published studies. Med Oncol. 2011;28:753-65.

14. Braam Kl, van der Torre $P$, Takken $T$, Veening MA, van Dulmen-den Broeder E, Kaspers GJ. Physical exercise training interventions for children and young adults during and after treatment for childhood cancer. Cochrane Database Syst Rev. 2016;3, CD008796.

15. Tan SY, Poh BK, Chong HX, Ismail MN, Rahman J, Zarina AL, Juraida ARE, Tahir A, Ruzita AT, Roslee R, et al. Physical activity of pediatric patients with acute leukemia undergoing induction or consolidation chemotherapy. Leuk Res. 2013:37:14-20.

16. Guiraud T, Nigam A, Gremeaux V, Meyer P, Juneau M, Bosquet L. High-intensity interval training in cardiac rehabilitation. Sports Med. 2012;42:587-605.

17. Devin JL, Sax AT, Hughes Gl, Jenkins DG, Aitken JF, Chambers SK, Dunn JC, Bolam KA, Skinner TL. The influence of high-intensity compared with moderate-intensity exercise training on cardiorespiratory fitness and body composition in colorectal cancer survivors: a randomised controlled trial. J Cancer Surviv. 2015. doi:10.1007/s11764-015-0490-7.

18. Edvardsen E, Skjonsberg OH, Holme I, Nordsletten L, Borchsenius F, Anderssen SA. High-intensity training following lung cancer surgery: a randomised controlled trial. Thorax. 2015;70:244-50.

19. Chamorro-Vina C, Ruiz JR, Santana-Sosa E, Vicent MG, Madero L, Perez M, Fleck SJ, Perez A, Ramirez M, Lucia A. Exercise during hematopoietic stem cell transplant hospitalization in children. Med Sci Sports Exerc. 2010;42: 1045-53.

20. San Juan AF, Chamorro-Vina C, Moral S, del Valle MF, Madero L, Ramirez M, Perez M, Lucia A. Benefits of intrahospital exercise training after pediatric bone marrow transplantation. Int J Sports Med. 2008;29:439-46.

21. Baumann FT, Bloch W, Beulertz J. Clinical exercise interventions in pediatric oncology: a systematic review. Pediatr Res. 2013;74:366-74.

22. Kesting S, Gotte M, Winter C, Rosenbaum D, Boos J. Physical activity and exercise after treatment for childhood cancer. Oncol Res Treat. 2014;37:120-1.

\section{Submit your next manuscript to BioMed Central and we will help you at every step:}

- We accept pre-submission inquiries

- Our selector tool helps you to find the most relevant journal

- We provide round the clock customer support

- Convenient online submission

- Thorough peer review

- Inclusion in PubMed and all major indexing services

- Maximum visibility for your research

Submit your manuscript at www.biomedcentral.com/submit
Biomed Central 